07

\title{
Исследование влияния легирования на переходные слои анизотипных гетероструктур на основе GalnAsP и InP, полученных методом МОС-гидридной эпитаксии
}

\author{
(C) Г.С. Гагис ${ }^{1}$, В.И. Васильев ${ }^{1}$, Р.В. Левин ${ }^{1}$, А.Е. Маричев ${ }^{1}$, Б.В. Пушный ${ }^{1}$, В.И. Кучинский ${ }^{1,2}$, \\ Д.Ю. Казанцев ${ }^{1}$, Б.Я. Бер ${ }^{1}$ \\ ${ }^{1}$ Физико-технический институт им. А.Ф. Иофффе РАН, Санкт-Петербург, Россия \\ ${ }^{2}$ Санкт-Петербургский государственный электротехнический университет „ЛЭТИ“, Санкт-Петербург, Россия \\ E-mail: galina.gagis@gmail.com
}

Поступило в Редакцию 10 июня 2020г.

В окончательной редакции 30 июня 2020г.

Принято к публикации 30 июня 2020 г.

\begin{abstract}
При исследовании легированных анизотипных гетероструктур со слоями $\mathrm{Ga}_{1-x} \operatorname{In}_{x} \mathrm{As}_{y} \mathrm{P}_{1-y}$, выращенных на подоложках InP c буферным слоем InP методом MOC-гидридной эпитаксии, в слое $\mathrm{Ga}_{1-x} \operatorname{In}_{x} \mathrm{As}_{y} \mathrm{P}_{1-y}$ со стороны подложки для отдельных образцов выявлено наличие переходных областей, на протяжении которых содержание мышьяка $(y)$ увеличивалось от границы со слоем InP к поверхности структуры на величину $\Delta y$ до 0.15 , а содержание элементов третьей группы $(x)$ оставалось постоянным.
\end{abstract}

Ключевые слова: МОС-гидридная газофазная эпитаксия, гетероструктуры, фотоэлектрические преобразователи, легирование, однородность.

DOI: 10.21883/PJTF.2020.19.50039.18419

В рамках безалюминиевых технологий материалами активных слоев фотоэлектрических преобразователей (ФЭП) для лазерного излучения с длиной волны $1064 \mathrm{~nm}$ могут быть твердые растворы $\mathrm{Ga}_{1-x} \mathrm{In}_{x} \mathrm{As}_{y} \mathrm{P}_{1-y}$, изопериодические c InP [1]. Активные слои должны иметь постоянный состав и высокую степень кристаллического совершенства на протяжении всей толщины (более $1 \mu \mathrm{m})$. Исследование однородности слоев таких материалов главным образом связано с изучением распределения легирующих примесей по толщине структуры $[1,2]$. В настоящей работе также изучалось распределение содержания матричных элементов $\mathrm{Ga}, \mathrm{In}$, As и $\mathrm{P}$ по толщине слоев $\mathrm{Ga}_{1-x} \operatorname{In}_{x} \mathrm{As}_{y} \mathrm{P}_{1-y}$.

Ранее [3] мы обнаружили, что при выращивании эпитаксиальных слоев $\mathrm{Ga}_{1-x} \operatorname{In}_{x} \mathrm{As}_{y} \mathrm{P}_{1-y}$ с составами $x=0.8-0.9, y=0.1-0.4$ методом газофазной эпитаксии из металлоорганических соединений и гидридов (МОС-гидридной эпитаксии) в некоторых случаях наблюдается градиент содержания элементов пятой группы $\Delta y$ по толщине практически всего эпитаксиального слоя (0.6-1.2 $\mu \mathrm{m})$ величиной $|\Delta y|$ до 0.1, несмотря на то что условия в реакторе (температура, давление, состав газовой смеси) в процессе осаждения слоя поддерживаются постоянными. Возникновение подобных неоднородностей мы связывали с деформациями кристаллической решетки осаждающегося эпитаксиального слоя, возникающими при его рассогласовании с предыдущим слоем. Согласно [4], подобные деформации могут влиять на встраивание компонентов пятой группы. Однако по мере формирования эпитаксиального слоя часть деформаций снимается за счет появления дислокаций несоответствия, и влияние предыдущего слоя ослабевает, в результате величина деформаций снижается [5]. Повысить однородность состава эпитаксиального слоя можно за счет подбора оптимальных параметров осаждения [3]. Однако при изменении некоторых условий формирования матрицы раствора $\mathrm{Ga}_{1-x} \operatorname{In}_{x} \mathrm{As}_{y} \mathrm{P}_{1-y}$, например при добавлении в газовую смесь прекурсоров легирующих примесей или при изменении их типа, также могут появляться неоднородности в распределении матричных компонентов.

Исследованные в настоящей работе гетероструктуры изготавливались на установке для МОС-гидридной эпитаксии AIX200 при давлении $0.1 \mathrm{~atm}$ на подложках $\operatorname{InP}(100): \mathrm{S}$ и $\operatorname{InP}:$ Те. Все подложки были разориентированы на $4^{\circ}$ к плоскости (111)A. Температура эпитаксиального роста была равна $600^{\circ} \mathrm{C}$, поток водорода через реактор составлял $5 \mathrm{slpm}$, прекурсорами легирующих примесей $\mathrm{Te}, \mathrm{Zn}$ и $\mathrm{Si}$ были диэтилтеллур (DETe), диэтилцинк $(\mathrm{DEZn})$ и силан $\left(\mathrm{SiH}_{4}\right)$. Прекурсорами матричных компонентов кристалла были арсин $\left(\mathrm{AsH}_{3}\right)$, фосфин $\left(\mathrm{PH}_{3}\right)$, триметилиндий (TMIn) и триэтилгаллий (TEGa). Потоки прекурсоров компонентов основной матрицы при выращивании слоев InP были равны $X_{\mathrm{TMIn}}=26 \mu \mathrm{mol} / \mathrm{min}, X_{\mathrm{PH}_{3}}=7812 \mu \mathrm{mol} / \mathrm{min}(\mathrm{V} / \mathrm{III}=300)$, при выращивании слоев $\mathrm{Ga}_{1-x} \operatorname{In}_{x} \mathrm{As}_{y} \mathrm{P}_{1-y}$ они составляли $X_{\mathrm{TEGa}}=2 \mu \mathrm{mol} / \mathrm{min}, \quad X_{\mathrm{TMIn}}=18 \mu \mathrm{mol} / \mathrm{min}$, $X_{\mathrm{PH}_{3}}=1696 \mu \mathrm{mol} / \mathrm{min}, X_{\mathrm{AsH}_{3}}=16 \mu \mathrm{mol} / \mathrm{min}(\mathrm{V} / \mathrm{III}=86)$ и на протяжении всего времени осаждения слоя (30-90 min) оставались постоянными. Несмотря на это, в слоях $\mathrm{Ga}_{1-x} \operatorname{In}_{x} \mathrm{As}_{y} \mathrm{P}_{1-y}$ легированных гетероструктур наблюдались увеличение содержания мышьяка и уменьшение содержания фосфора $|\Delta y|$ от границы с буферным слоем InP к поверхности гетероструктуры, 


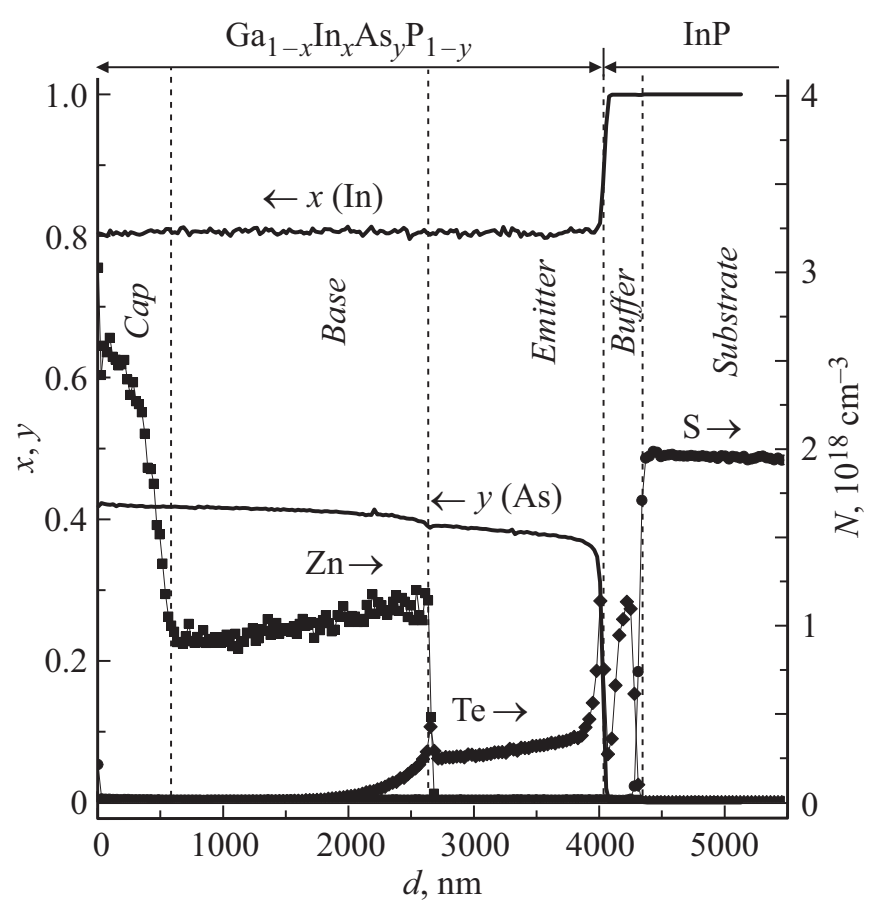

Рис. 1. Распределение содержания элементов третьей группы $(x)$, пятой группы $(y)$, а также объемной концентрации легирующих примесей $N$ по толщине $d$ гетероструктуры $Ф Э П$.

в отдельных случаях, согласно данным вторичной ионной масс-спектрометрии (ВИМС), они достигали значения $|\Delta y|=0.15$, что превышает величины, полученные нами при исследовании нелегированных слоев $\mathrm{Ga}_{1-x} \operatorname{In}_{x} \mathrm{As}_{y} \mathrm{P}_{1-y}$ [3], где максимальное значение $|\Delta y|$ составило 0.10 .

Одна из исследованных в работе гетероструктур использовалась ранее для формирования ФЭП на длину волны $1064 \mathrm{~nm}$, характеристики которого были представлены в работе [1]. При изготовлении структуры ФЭП были использованы следующие режимы роста: на подложке InP:Te в течение 20 min выращивался буферный слой InP:Te (Buffer), $X_{\mathrm{DETe}}=0.012 \mu \mathrm{mol} / \mathrm{min}$, далее делалась пауза $60 \mathrm{~s}$, в течение которой через реактор продувался чистый водород, затем в течение $90 \mathrm{~min}$ выращивался эмиттерный слой $\mathrm{Ga}_{1-x} \operatorname{In}_{x} \mathrm{As}_{y} \mathrm{P}_{1-y}: \mathrm{Te}$ (Emitter $), X_{\mathrm{DETe}}=0.007 \mu \mathrm{mol} / \mathrm{min}$, и снова делалась пауза $60 \mathrm{~s}$. Далее в течение $150 \mathrm{~min}$ выращивался слойбаза $\mathrm{Ga}_{1-x} \operatorname{In}_{x} \mathrm{As}_{y} \mathrm{P}_{1-y}: \mathrm{Zn}$ (Base), $X_{\mathrm{DEZn}}=0.2 \mu \mathrm{mol} / \mathrm{min}$. После этого в течение $30 \mathrm{~min}$ осуществлялся рост слоя $\mathrm{Ga}_{1-x} \operatorname{In}_{x} \mathrm{As}_{y} \mathrm{P}_{1-y}: \mathrm{Zn}$ (Cap), в ходе осаждения которого поток DEZn менялся с 0.2 до $1 \mu \mathrm{mol} / \mathrm{min}$, таким образом формировался контактный слой. Исследования структуры ФЭП методом ВИМС показало влияние легирующей примеси на распределение элементов пятой группы по толщине слоя (рис. 1). На границе перехода между областями, одна из которых легирована теллуром (рис. 1, область Emitter), а вторая - цинком (рис. 1, область Base), наблюдался излом в распределении элементов пятой группы по толщине слоя (рис. 1, кривая для As), в то время как для элементов третьей группы подобного излома не наблюдалось (рис. 1, кривая для In).

Излом между областями Emitter и Base может быть связан с несколькими факторами. Во-первых, это замена в составе газовой смеси прекурсора теллура на прекурсор цинка. В отличие от теллура цинк склонен активно взаимодействовать с прекурсорами фосфора и мышьяка, в результате чего образуются прочные летучие соединения $\mathrm{Zn}_{3} \mathrm{P}_{2}, \mathrm{Zn}_{3} \mathrm{As}_{2}$, причем фосфор связывается в газовой фазе более активно, чем мышьяк, поскольку соединения с фосфором имеют более прочные химические связи. О прочности химических связей можно судить по стандартным энтальпиям образования $\Delta H_{298}^{0}$ и температурам конгруэнтного плавления $T^{F}$, которые для $\mathrm{Zn}_{3} \mathrm{As}_{2}$ составляют $\Delta H_{298}^{0}=-143.4 \mathrm{~kJ} / \mathrm{mol}$ [6] и $T^{F}=1288 \mathrm{~K}$ [6], а для $\mathrm{Zn}_{3} \mathrm{P}_{2} \Delta H_{298}^{0}=-176.1 \mathrm{~kJ} / \mathrm{mol}$ [6] и $T^{F}=1453 \mathrm{~K}$ [7]. В результате осаждающаяся твердая фаза оказывается более обедненной фосфором и более обогащенной мышьяком по сравнению с ситуацией, когда в газовой фазе отсутствует прекурсор цинка. Во-вторых, это пауза в $60 \mathrm{~s}$, во время которой могла произойти частичная деградация поверхности, в ходе которой изменились ее свойства. В-третьих, на состав осаждающегося слоя $\mathrm{Ga}_{1-x} \mathrm{In}_{x} \mathrm{As}_{y} \mathrm{P}_{1-y}$ оказывает влияние легирование предыдущего слоя, что наблюдалось нами на образцах гетероструктур $B 1$ и $B 2$, которые состояли из трех слоев: $\mathrm{InP} / \mathrm{Ga}_{1-x} \operatorname{In}_{x} \mathrm{As}_{y} \mathrm{P}_{1-y} / \mathrm{InP}$. После выращивания каждого из слоев гетероструктур $B 1-B 2$ делались паузы в подаче всех прекурсоров на $60 \mathrm{~s}$. Верхние слои - Cap InP - у обеих структур выращивались одинаково: в течение $45 \mathrm{~min}$ и не легировались. Средние слои - Active $\mathrm{Ga}_{1-x} \mathrm{In}_{x} \mathrm{As}_{y} \mathrm{P}_{1-y}$ - также для обеих структур имели одинаковые режимы получения: осаждались в течение $120 \mathrm{~min}$ и легировались цинком с потоком прекурсора $X_{\mathrm{DEZn}}=0.2 \mu \mathrm{mol} / \mathrm{min}$; согласно ВИМС, концентрация цинка составила около $1 \cdot 10^{18} \mathrm{~cm}^{-3}$. Однако легированные цинком слои

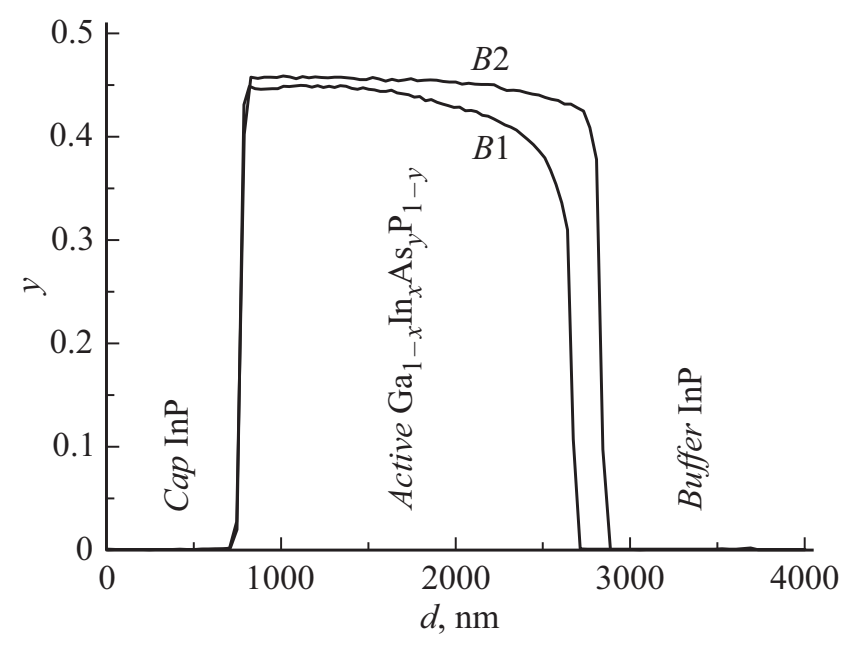

Рис. 2. Профиль распределения содержания мышьяка (y) по толщине гетероструктуры $d$ для образцов $B 1$ и $B 2$. 
$\mathrm{Ga}_{1-x} \mathrm{In}_{x} \mathrm{As}_{y} \mathrm{P}_{1-y}$ осаждались на разных буферных слоях. Оба буферных слоя выращивались в течение $45 \mathrm{~min}$, но в случае $B 1$ буферный слой InP был легирован теллуром $\left(X_{\mathrm{DETe}}=0.006 \mu \mathrm{mol} / \mathrm{min}\right)$, а в случае $B 2$ кремнием $\left(X_{\mathrm{SiH}_{4}}=0.4 \mu \mathrm{mol} / \mathrm{min}\right)$. Измеренная методом ВИМС концентрация легирующих примесей в буферном слое как для $B 1$, так и для $B 2$ составила $2 \cdot 10^{18} \mathrm{~cm}^{-3}$. Однако, как можно видеть из рис. 2, согласно ВИМС, слои $\mathrm{Ga}_{1-x} \mathrm{In}_{x} \mathrm{As}_{y} \mathrm{P}_{1-y}$, выращенные на разных буферных слоях, имеют различные толщины, а зависимость содержания мышьяка от толщины слоя возле границы со слоем Buffer InP имеет различную форму.

Таким образом, легирование влияет на соотношение количеств атомов пятой группы в эпитаксиальных слоях $\mathrm{Ga}_{1-x} \operatorname{In}_{x} \mathrm{As}_{y} \mathrm{P}_{1-y}$. Также наблюдается влияние свойств буферного слоя InP на формирование слоя $\mathrm{Ga}_{1-x} \mathrm{In}_{x} \mathrm{As}_{y} \mathrm{P}_{1-y}$. Это явление необходимо учитывать при выращивании $p-n$-гетероструктур для высокоэффективных ФЭП нового поколения.

\section{Финансирование работы}

Исследования методом ВИМС проводились с использованием оборудования ЦКП „Материаловедение и диагностика в передовых технологиях“ (ФТИ им. А.Ф. Иоффе), поддерживаемого Министерством науки и высшего образования РФ (уникальный идентификатор проекта RFMEFI62119X0021).

\section{Конфликт интересов}

Авторы заявляют, что у них нет конфликта интересов.

\section{Список литературы}

[1] Хвостиков В.П., Сорокина С.В., Потапович Н.С., Левин Р.В., Маричев А.Е., Тимочина Н.Х., Пушный Б.В. // ФТП. 2018. Т. 52. В. 13. С. 16411646. DOI: 10.21883/FTP.2018.13.46880.8926 [Пер. версия: $10.1134 / \mathrm{S} 1063782618130079]$.

[2] Razeghi M. MOCVD challenge. Survey of GaInAsP-InP \& GaInAsP-GaAs for photonic and electronic device applications. 2ed. Taylor and Francis/CRC Press, 2010. 773 p.

[3] Гагис Г.С., Левин Р.В., Маричев А.Е., Пушный Б.В., Щеглов М.П., Бер Б.Я., Казанщев Д.Ю., Кудрявщев Ю.А., Власов А.С., Попова Т.Б., Чистлков Д.В., Кучинский В.И., Васильев В.И. // ФТП. 2019. Т. 53. В. 11. С. 15121518. DOI: 10.21883/FTP.2019.11.48446.9191 [Пер. версия: $10.1134 / \mathrm{S} 106378261911006 \mathrm{X}]$.

[4] Cunningham J.E., Santos M.B., Goossen K.W., Williams M.D., Jan W. // Appl. Phys. Lett. 1994. V. 64. P. 2418-2420.

[5] Beanland R., Dunstan D.J., Goodhew P.J. // Adv. Phys. 1996. V. 45. P. 87-146.

[6] Binnewies M., Mike E. Thermochemical data of elements and compounds. 2ed. Weinheim: Wiley-VCH Verlag GmbH, 2002. $926 \mathrm{p}$.

[7] Zdanowicz W., Henkie Z. // Bull. Acad. Pol. Sci. Ser. Sci. Chem. 1964. V. 12. P. 729-734. 